\title{
Parody and Caricature in the Satirical Weeklies: Conventions of Perception and Conflict of Interpretations
}

\author{
Alexey Kozlov, and Anastasia Vasilenko \\ Institute of Philology, Mass-Media and Psychology, Novosibirsk State Pedagogical University, \\ Viluyskaja Str., 28, 630128 Novosibirsk, Russia
}

\begin{abstract}
The article is devoted to the interpretation of parody, satire, and caricature within the framework of premodern, modern, and postmodern societies. Considering mainly Western European and Russian cases, the researchers conclude that system of regulations and conventions linked the addressee and the addresser. The article compares some of the strategies and reputational capabilities of the satirical weeklies "Charivari", "Punch", "Spark", "Alarm clock" and "Dragonfly", an attempt is made to rank these publications according to the degree of public consent and disturbance of the public peace. Finally, conclusions are drawn about taboos and topics prohibited by the legal or moral law, the appeal to which has a clearly conflicting potential.
\end{abstract}

\section{Introduction}

The origins of the parody as a cultural genre suggest a complex interaction of empirical and aesthetic reality [1]. Starting with Ancient comedies and finding "low analogs" of high genres in the culture of the Middle Ages and the Renaissance, it can be stated that the general parodical mechanism consists in extracting some object (personality, precedent text, episode of political or ideological struggle) from a number of similar ones and giving it comic properties and shades [2]. There are components traditionally revealed: travesty or derogative of a high standard, inversion of the head and bottom, reducing the phenomenon of a normative order to a non-normative one in the cultural analysis of works in a wide range. From Aristophanes to Rabelais, from Annoyed Bacchus by V. Maikov to the House of Crazy by A.I. Voejkov [3-5] we can find same cases in different cultures.

The modern culture perceives parody as one of the possible registers that assert itself in all normative kinds of literature. Explication of parodic properties, as $\mathrm{Yu}$. Tynyanov rightly noted, becomes one of the factors of literary evolution [6,7]. Thus, William Thackeray's Vanity Fair continued the deconstruction of the Walter Scott type novel, while Gustave Flaubert's Madame Bovary, becoming an anti-novel, reflected the weaknesses of Charles Dickens's poetics and refuted the logic of constructing a boudoir novel of the 19th century. It should be noted that in all these cases, the story is not confined to parody, but the case has become an important component in the study of genre and content of polyphony.

In general, we can say that there are three main types of parody:

1. Parodying the form of oral or written speech, pictorial or literary style; 
2. Parody of external or internal features of personality behavior;

3. Profanation (anti-sacralization) and bringing to the point of absurdity (reductio ab absurdum).

Each of the types of parody involves the search and approval of forms of social agreement between the addressee of the parody and the addressee. Without this agreement, parody becomes a mental weapon, often violating boundaries established by law or morality, posing a threat to tolerance and tolerance.

\section{Materials and Methods}

Cartoons and satirical texts of the New Age (for example, periodicals of the 19th century) have become the main material for the research. So cases and examples (which were founded in history of the journalism) can be projected onto contemporary postmodern society.

In the field of mass communication, parody also played a significant role in satirical weekly. It became one of the languages of everyday life: Charivari in France, Punch in Victorian England, Spark (Iskra), Alarm Clock and Dragonfly in Russia created some semblance of an anti-world, undermining trust in normative patterns.

Table 1. Satirical Weeklies: country and years

\begin{tabular}{|c|c|c|}
\hline Country & Magazines & Years \\
\hline France & Charivari & $1832-1937$ \\
\hline England & Punch & $1841-1992,1996-2002$ \\
\hline \multirow{2}{*}{ Russia } & Spark (Iskra) & $1859-1873$ \\
\cline { 2 - 3 } & Dragonfly & $1875-1908,1915-1918$. \\
\cline { 2 - 3 } & Alarm Clock & $1873-1917$ \\
\hline
\end{tabular}

The interpretation of these publications as a kind of supertext not only allows one to get an idea of the informational picture of the world and the agenda, but also to determine the basic techniques used by the players of the literary and journal field when choosing a certain strategy. Each satirical weekly can be presented as a polycode text [8]. Based on the concept of creolized texts, we understand this phenomenon as "texts whose texture consists of two inhomogeneous parts: verbal (linguistic / speech) and non-verbal (belonging to other sign systems than natural language)". Following E E. Anisimova, speaking about written communication as the dominant of the field of paralinguistic means, we consider iconic (pictorial) means [9-11]. Iconic elements play a significant role in the mechanisms of generating meaning, presenting the author's position and interpreting the text as a whole.

The text of a caricature, especially one accompanied by a signature, is a creolized, semiotically complicated text with multiple textual references. Being embedded in the text of the journal, the cartoons organize a syntagmatic sequence in which their correlation in the publication, the connection with the accompanying text (articles), and signatures are significant. It should also be remembered that a caricature is an integral part of the graphic code of a publication, both meeting the reader's expectations and violating them. The interpretation of a caricature presupposes mastery of the means of iconic and verbal codes. It is desirable for the reader to know the source code (the humorous potential is realized when the interpretational attitudes of the source text collide (with often literal reproduction) and the creolized text). This presupposes knowledge of the facts of extra-linguistic reality: cultural and historical context, social and socio-political processes, etc. Often, these components are lost in the modern interpretation: outside the context of the era, the reader 
may misunderstand some meanings, for his references become opaque, which did not present difficulties for readers who are contemporaries of the publication.

\section{Results and Discussion}

The reason why illustrated satirical editions have won their place in the book and magazine culture of the New Time is their topicality and a kind of encyclopedism: episodes of foreign policy and domestic life, events of the cultural (and, in particular) literary world are reflected on the pages of weeklies [12]. The satirical weekly opposes an antiworld to a rationalized and ordered reality that satisfies the philosophy of utilitarianism and reasonable egoism: a caricatured, deliberately reduced image of writers, politicians, ironic and satirical distortion of precedent texts. Thus, the popularity of illustrated satirical editions is determined by the internal demand for a carnival rethinking of serious topics and revision of the formed picture of the world.

In the one hand, the content of the popular weekly Punch is discordant with the demands of the Victorian world. However its more than a century history of existence suggests that the demand for such a discourse, regardless of the change in social formations, remained stable and high. Focusing on the Spectator tradition, on the other hand, Punch editors Marc Lemon and Genius Mayhew at the same time took into account the success of French publications (primarily Le Charivari). As R. Eltik notes, «Conquering the favor of the middle class, later reaching the top of society and becoming part of the reading of the elite, which entered all salons, living rooms and coffee houses, "Punch" became a household name» [13, p. 17]. The popularity of the publication is evidenced by both the circle of employees (including Charles Dickens and William Thackeray) and the readership (from Elizabeth Barrett and Robert Browning to Ralph Waldo Emerson and Henry Wadsworth Longfellow). Finally, Punch received unlimited credit: even "The Times" repeatedly created the necessary advertisement for the publication, turning to citation. Thus, Punch was built into the system of Victorian supply and demand, becoming an absolute long-liver in the environment of weeklies.

The story of the satirical weekly Iskra (1859-1873) turns out to be different. Finding readers from a bourgeois and democratic milieu, Iskra was perceived by them as one of the "departments of Sovremennik". Despite the encyclopedism noted above (assessed as "omnivorous"), Iskra failed to attract writers of the first literary series. Regularly printing cartoons of Turgenev, Pisemsky, Avdeev and Dostoevsky, creating a series of cartoons aimed at discrediting literary opponents, Iskra met the requirements of an undemanding addressee, but did not have the resource to strengthen its symbolic capital and expand its readership [14-17]. The strategy of literary struggle used by Vasily and Nikolai Kurochkin, on the one hand, made it possible to "destroy" in the eyes of the reader individual "thick magazines" ("The Time", "Native Notes", "Russian Bulletin" "Epoch", "World Labor", "Zarya") - the number of subscribers to these publications decreased every year [18]. On the other hand, the regular transition to personalities, the topical and witty description of the life of the Russian provinces created the aura of a predatory publication (it was considered dangerous to "get into Iskra"). Moreover, citing Iskra was possible only as a result of polemics. Government publications and newspapers that set the agenda usually avoided citing the weekly, and pressure from official institutions periodically arose: censorship bans, fines, and publication suspensions. After 1870, Iskra refuses to use illustrations: without cartoons, the publication becomes, according to A.A. Skabichevsky, "a fly without wings".

The Iskra weekly genetically related to the satirical journals of N.I. Novikov, N.I. Strakhov and I.A. Krylov, becomes a connecting link between "Whistle" as an appendix to the radical "Contemporary" and "Alarm clock" and "Dragonfly" - deliberately apolitical 
editions of the last third of the $19^{\text {th }}$ and beginning $20^{\text {th }}$ century. The revival on the pages of Iskra of the traditions of Drone (Letters to Falaley), Satirical Messenger (Lament of Fashion), Hellish Mail (Letters) is symptomatic: unresolved issues of social reality were interpreted as eternal, not losing their sharpness, relevance and topicality in the post-reform period.

At the same time, Iskra can be called a kind of "aggregator" of reviews and reputations of the 60s of the XIX century: by means of feuilleton, caricature, satire and anecdote, Kurochkin's publication became an agent of influence, influencing the reader, his tastes and preferences. Thus, the translations from Heine, Beranger, Barbier, and in recent years, Baudelaire, appearing on the pages of the weekly, set some patterns of behavior and style (not correlated with normative poetry), while numerous transcriptions of works of Russian classics ( including the textbook) served as material for ironic and satirical variations on well-known topics.

A comparison of the two weeklies, at first glance, demonstrates a paradox: the Punch, alien to Victorian ideology, finds both institutional and financial support, while a weekly published in post-reform Russia and serving as one of the "distorting mirrors" of the ongoing changes is gradually losing its significance. The explanation of this paradox lies in editorial approaches, strategies and tactics aimed at capturing the literary field, increasing symbolic capital, and prestige. The stability of Punch clearly contrasts with the short-term history of Iskra, which allows these two editions to see different scenarios for organizing the magazine business, reflecting the structure of other social institutions that influence both momentary success and recognition in the long term [19].

In this regard, Dragonfly and Alarm Clock are closer to the Punch. Satisfying the demands of the undemanding average reader, they enjoyed a steady demand and were closed only after the 1917 revolution. Moreover, when Vladimir Lenin was looking for a name for an illegal, radical publication of the Bolshevik press, he remembered Iskra and called his newspaper Iskra.

\section{Conclusions}

The above outline of history of satirical weeklies in Russia and Europe allows us to draw several significant conclusions.

1. Parody and satire in modern journalism is becoming an integral part of everyday life. That allows us to view the satirical weekly as a modern day and an encyclopedic chronograph in the aspect of history.

2. The life span of a satirical weekly is determined by economic, social and political factors. Firstly, it is the supply and demand system associated with the content of the publication. Secondly, topicality suits official and unofficial opinion leaders in equal measure. At the same time, topicality should not go beyond the permissible specific society. Third, it is a loyalty regime associated with the correspondence of political and ideological requests to the content of the newspaper.

3. Parody and caricature have enduring functions. In general, the phenomenon is connected with a decline of a high standard, profanation and anti-sacralization. Further, it is a conflicting attack on a contemporary (often associated with bullying, humiliation of honor and dignity). Moreover, this is an attempt to change the aesthetic and social realities, exacerbating their comic discrepancy. Finally, this is a momentary reflection aimed at finding evolutionary ways of developing mass communication and global dialogue.

4. Ideally, both the addressee and the addressee of the parody conclude an agreement. The meaning of the agreement is that both parties understand the border of the comic and can stop the game at any time. Violation of this simple principle threatens tolerance and social harmony and can be likened to the involvement of bystanders in the carnival who are 
not familiar with the rules and laws. The tragic consequences of such violations are clearly visible in today's postmodern society, which has questioned basic values, but still reacts painfully to violations of established boundaries [20]. The conflict of interpretations in discursive practices should not lead to conflict in social relations.

\section{Acknowledgements}

The research was supported by a grant from the President of the Russian Federation to support young scientists (MK-841.2020.6 "Iskra" (1859-1873) as Encyclopedia of Russian Life: publishing practices, plot mechanisms, genre modifications).

\section{References}

1. D. Fokkema, Literary history, modernism, and post modernism (1984)

2. M.A. Rose, Parody: Ancient, Modern, and Post-Modern (1993)

3. M.M. Bakhtin, Literature and aesthetics. Studies of different years (1973)

4. M.L. Gasparov, Parody. GSE (3rd edition) (1975)

5. V.Sh. Krivonos, Parody. Poetics (2008)

6. Yu.N. Tynyanov, Dostoevsky and Gogol: to theory of parody. Poetics. History of Literature and Cinema (1977)

7. Yu.N. Tynyanov, About parody. Literature Evolutions (2002)

8. N.E. Mednis, Critique and Semiotics, 6, 51 (2003)

9. I.R. Galperin, Text as an object of linguistic research (1981)

10. E.E. Anisimova, Linguistics and intercultural communication (based on creolized texts) (2003)

11. A.G. Vasilenko, Siberian Journal of Philology, 1 (2016)

12. A.I. Reytblat, From Bova to Balmont and other works of Historical Sociology of the Russian literature (2009)

13. R. Altick, Punch: The Lively Youth of a British Institution (1997)

14. I. Jampol'skij, Satirical Magazines of 60th of XIX century (1964)

15. V.N Rumjanceva, Poetry Fellieton of middle of XIX century: N.A. Nekrasov, V.S. Kurochkin, D.D. Minaev (2007)

16. E.V. Tselikova, Periodical Figure of A.A. Fet in "Iskra" (2007)

17. E.V. Tselikova, Herzen University Journal of Humanities \& Sciences, 11 (32) (2007)

18. A.E. Kozlov, Vestnik NSU Series History and Philology, 19 (6) (2020)

19. P. Bourdieu, Rules of Art: Genesis and Structure of the Literary Field (1996)

20. P. Ricœur, Conflict of Interpretations (2003) 